\title{
Finite-element model of a rigid wing sail for a maxi trimaran
}

\author{
Hervé Devaux ${ }^{a}$, Rémy Balze and Steven Robert \\ HDS, 45 rue de l'Elorn, 29200 Brest, France
}

Received 10 February 2012, Accepted 16 November 2012

\begin{abstract}
Since 1994, HDS is a major player in the design of complex composite parts, especially for racing sailing yachts [1]. In this paper, we suggest to present our approach in the design and finite-element modelling of the rigid wing-sail of the trimaran that won the 33rd America's Cup, held in February 2010. From the decision to design the wing-sail to the assembly on the maxi trimaran, we will present the different steps of design and computation: principles and assessment of the aerodynamic loads, structural design and modelling with tools adapted to each problem, mass optimization. Then, we will detail some of the numerical problems that we faced in this project.
\end{abstract}

Key words: HDS / rigid wing-sail / sailing yacht / trimaran / finite-elements / modeling / design

Résumé - Modélisation éléments-finis d'une voile rigide pour un maxi trimaran. Depuis 1994, la société HDS est un des acteurs majeurs dans la conception de pièces composites complexes, notamment dans le nautisme de compétition [1]. Dans cet article, nous proposons de présenter notre démarche dans la conception et la modélisation éléments-finis de l'aile rigide du trimaran vainqueur de la $33^{\mathrm{e}}$ Coupe de l'America, qui a eu lieu en février 2010. Depuis le choix de concevoir l'aile jusqu'au montage sur le maxi trimaran, nous présenterons les différentes étapes de conception et de calcul : principes et définition des chargements aérodynamiques, conception structurelle et modélisation par les outils adaptés à chaque problématique, optimisation de la masse. Nous détaillerons enfin quelques-uns des problèmes numériques auxquels nous avons été confrontés dans ce projet.

Mots clés : HDS / aile rigide / voilier / trimaran / éléments-finis / modélisation / conception

\section{Nomenclature}

\begin{tabular}{|ll|}
\hline$\backslash \backslash /]$ & $+/-45^{\circ}$ composite ply \\
{$[l]$} & unidirectional ply oriented along \\
& the principal direction \\
{$[\#]$} & Nomex $48 \mathrm{~kg} \cdot \mathrm{m}^{-3}$ core, $8 \mathrm{~mm}$ thick \\
$\sigma_{\text {cruD }}$ & $\begin{array}{l}\text { Critical stress in unidirectional } \\
\text { composite fiber (buckling calculation), in } \mathrm{MPa}\end{array}$ \\
Pcr & Critical load (buckling calculation), in $\mathrm{kN}$ \\
\hline
\end{tabular}

\section{Introduction}

The 33rd America's Cup began with a legal battle at the New York Justice Court in the summer of 2007. The american challenger BMWOracle filed an appeal against the swiss Defender Alinghi to contest the choice of the Spanish Challenger as Challenger of Record ${ }^{1}$. The result

\footnotetext{
a Corresponding author: hdv@hds-design.com

1 The Challenger of Record is the leader of Challengers. It is designated by the defender which won the previous America's
}

of these lawyer debates gave birth to two giant multihulls optimized for regatta. In the race to design, the two contenders, Alinghi and BMWOracle, competed with ingenuity and gigantism: large and powerful platforms, rigs with huge proportions. The rigid wing-sail designed and built by BMW Oracle Racing team stands for the pinnacle of this development.

From the first sketches, HDS has been involved in the design of the American trimaran. After some feasibility pre-studies on performance and mass, in which HDS is closely associated, the final construction decision was taken on the 1st of April 2009. The regatta is scheduled for early February 2010, the wing must sail in November 2009; six months of intense calculations/designs start, in parallel with the construction!

In a first step, we will present the calculation methods of structures that have been implemented to achieve an efficient and pragmatic definition of the wing-sail. In a

Cup. Together, they will define the Rules for the next America's Cup. 


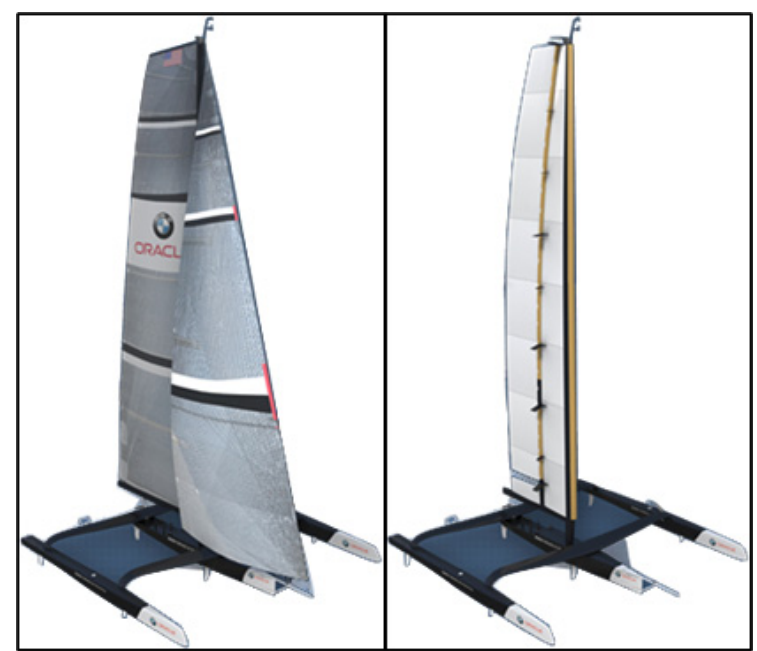

Fig. 1. The trimaran with soft sails faced to the trimaran with wing-sail.

second step, we will precise some numerical pitfalls which we encountered during this project, and also in the past.

\section{Aerodynamics - structure synergy}

The "mast + sail" package for a classic rig or a "wing" is the engine of the boat. This element must produce the thrust that will propel the sailing yacht. Aerodynamicists are optimizing their sail plan in terms of lift and drag reduction, whereas structural engineers are looking for a reliable and lightweight package. Coordination of these two groups of designers is key of success.

\subsection{Aerodynamic principles}

To better understand the choice of a wing-sail, let's compare the two options of "propelling system" (Fig. 1). A mast/sail package has a lift coefficient of about 1.2 for a surface of $1100 \mathrm{~m}^{2}$. The objective of the rigid wing-sail is to work with higher lift coefficients, around 2.5, then the surface of the wing is reduced to $650 \mathrm{~m}^{2}$ with a wingspan of $67.5 \mathrm{~m}$ (Fig. 2).

Alongside of obvious advantages for the wing-sail in terms of performance lie some unknown challenges: among them, one can think about the fact of not being able to reduce its surface, a mass of structure to be evaluated, and maintenance support to be invented.

\subsection{Specifications}

The wing-sail or the mast rigging must transmit the sailing load to the platform to make it go forward. Sailing load is produced by the wind, and the goal is to sail with wind speed from 5 knots to 25 knots. This implies the requirement to be able to reduce the power generated by the sail plan in strong wind.
On a rigid wing-sail, this means changing the airfoil shape. Made of a fixed main element and 9 adjustable flaps, the rigid wing-sail is trimmed by incidence, camber, and twist (Fig. 3). The main challenge is to create a twist profile line. This is achieved by setting different angles at each flap control station. As a consequence, to respect continuity in the twist profile line, the torsional stiffness properties of the flaps must be accurately defined.

\subsection{Structural design}

In the initial design of the wing-sail, we have a geometry and targets of twist to achieve. Our first analysis is to define the primary structure based on the basic loadpath.

In the section view, the wing is made of two parts: the main element and the 9 flaps behind, distributed evenly along the span (Fig. 4). The orientation of flaps is controlled by control arms shown on the right part of Figure 4.

The main element is linked to the platform to transfer the thrust load and the compression induced by the rigging. To respect this load path in an efficient way, the core of the Main Element is a "main spar", that is then shaped with fairing elements on leading and trailing edges. This structural spar carries all global loads: global bending/compression/torsion of the wing. The shape of this spar (chord/thickness) is defined such as inducing the best efficiency of the carbon fibers.

The flaps are designed to transmit aerodynamic forces to the main element and produce the camber and the twist profile of the wing; thus, the main design criterion of flap spars are a reasonnable bending on aerodynamic loads, and a moderate torsional stiffnesss to ensure an efficient global flying shape. The rest of a flap element is a fairing required only to achieve a good aerodynamic shape.

\section{Tools dedicated to each design topic}

During the structural design phase, many computation methods have been implemented. In this section we present some of the in-house software used.

The wing-sail design starts with the use of analytical calculations completed by composite beam finite-element (FE) models (using in-house software). This first step essentially allows to design the main element main spar.

Then, for each structural pieces design, the approach contains the same steps:

- Analytical simple calculations to define first global dimensions of the structure (for example a typical section of a flap spar).

- Composite beam FE model (using in-house software), based on the analytical results, to have a first design of the studied structure. This step allows to rapidly modify some dimensions or adapt criteria if necessary.

- Detailed FE model to validate and optimize the first design. 


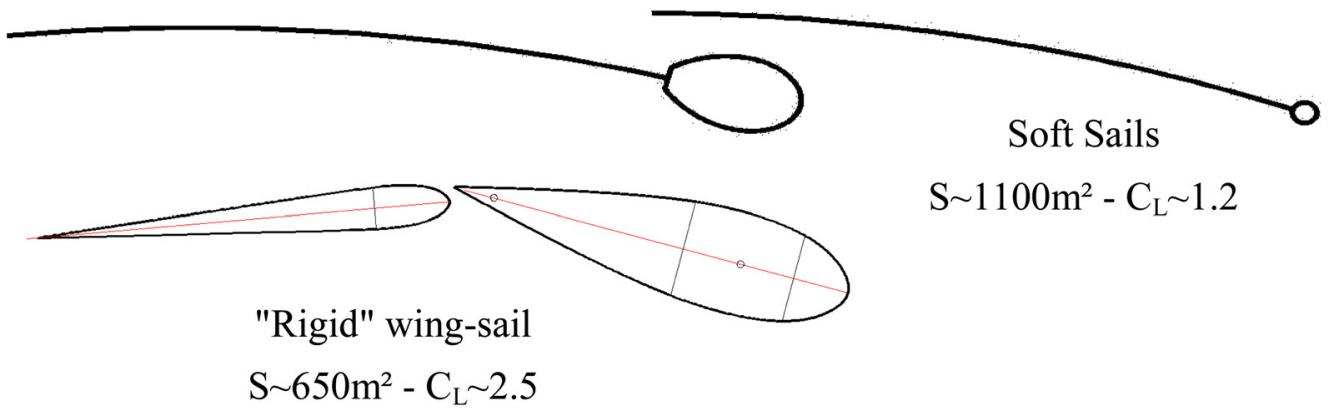

Fig. 2. Comparison between a wing-sail and a soft sail. $S$ is the surface, $C_{\mathrm{L}}$ is the lift coefficient.

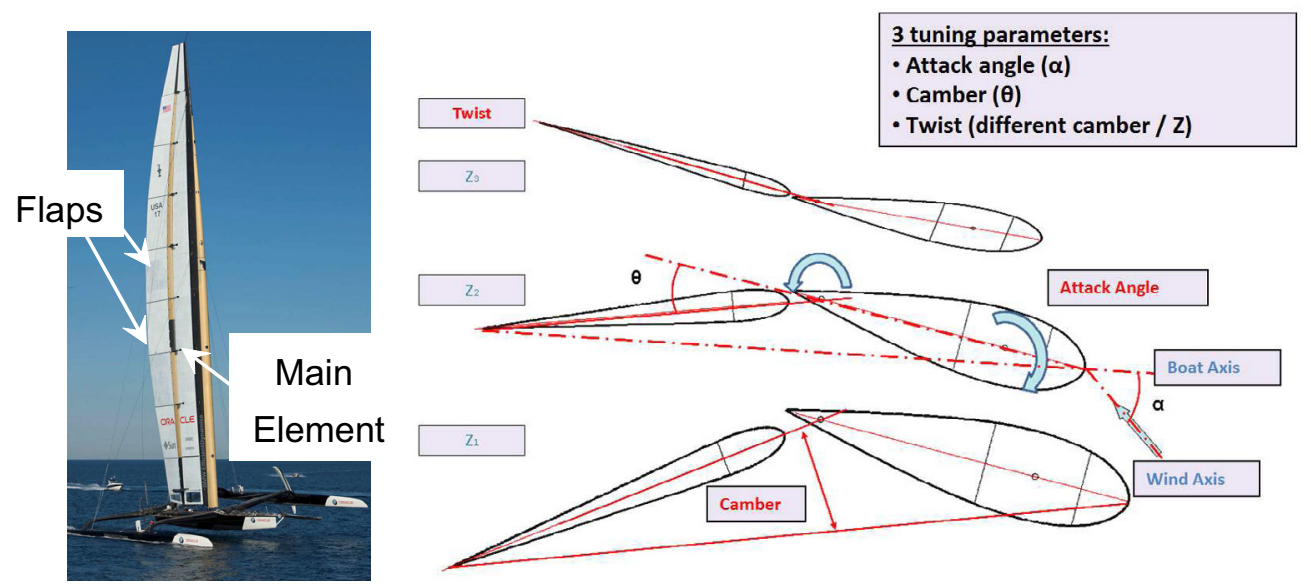

Fig. 3. Left: the wing-sail: main element and flaps. Right: the 3 tuning parameters: attack angle, camber and twist.

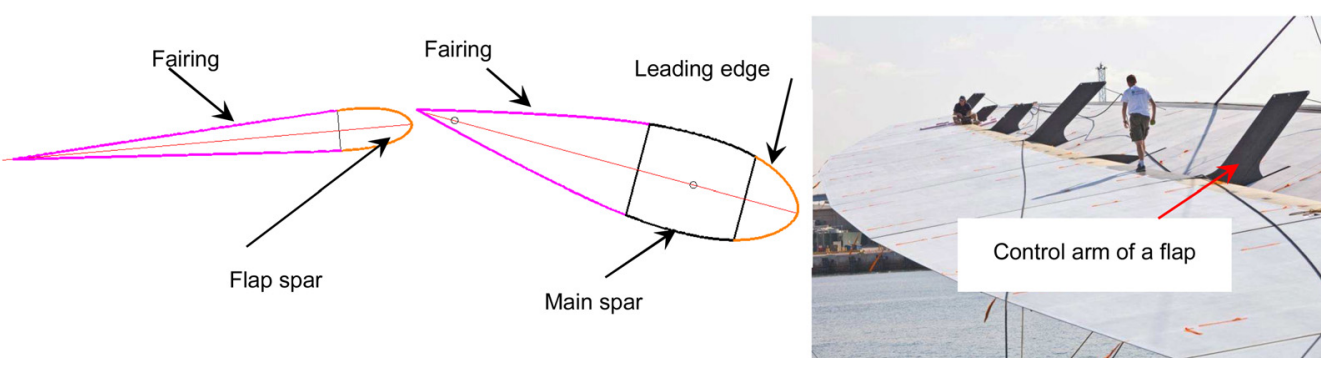

Fig. 4. Structural design.

Finally, an overall check is done by building a complete composite shell FE model of the main element structure. It allows to check the interactions between each part of the main element overall structure, particularly when it is deformed under the various loadcases, and to modify the geometry or the laminate of some part if necessary.

\subsection{Design and modelling of the global structure: AutoSpar}

AutoSpar/SimSpar is an in-house HDS FEA software developed for over 20 years to design rigs with strain buckling - stress criteria [2]. Thanks to this tool the designer can quickly explore many configurations, develop sensitivity analysis and run optimization processes.
To ensure a smooth rigid wing design, HDS developed new features in that software to take into account the specificity of loadcases and behavior of a wing.

Using this FE Software (Fig. 5), all the structure is modelled with simplified but accurate equivalent beam elements. Optimization of stiffness distribution can be carried out to define the main element main spar.

Various sailing configurations - upwind, downwind, wing alone - or various headsails are run to define the most severe loadcases in terms of strength, and also the accurate sailing configuration for a good definition of the global stiffness.

Thanks to this pre-study and feasibility study phase, the main element main spar was properly sized (geometry and laminate). Since the stiffness/mass distribution was closely related to the global geometry of this structural spar, numerous iterations between aerodynamicists and 


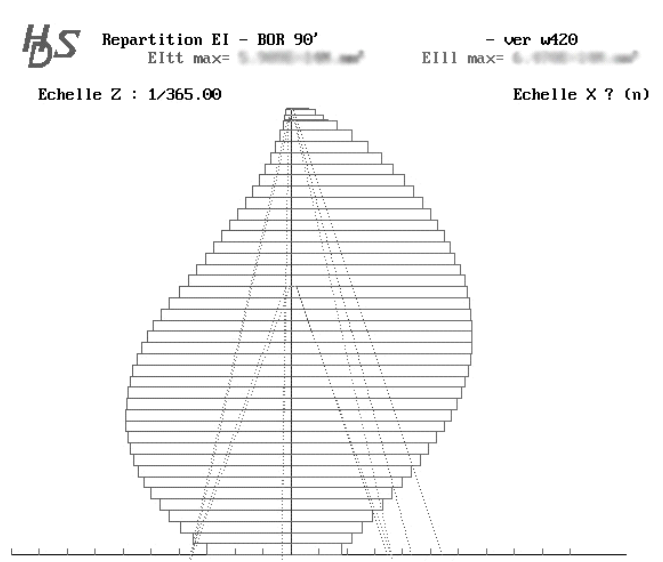

Stiffness distribution

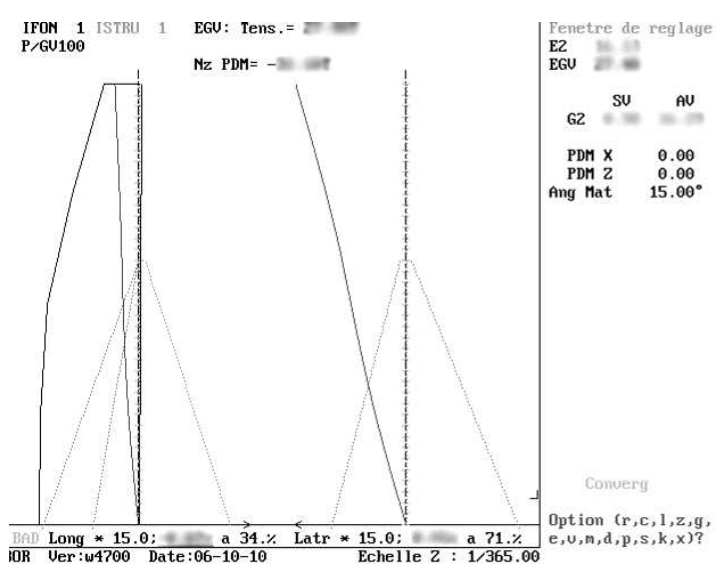

Wing-Sail Tune

Fig. 5. AutoSpar software. For confidentiality reasons, the values are blurred.

structural engineers were necessary to achieve the final optimum shape.

\subsection{Detailed modelling}

Analytical methods and software developed by HDS were used in the initial design phase to understand the overall behavior of each part of the structure. Once the overall concept was defined, each component was modelled thanks to commercial finite-element software (NX NASTRAN) using composite shell elements.

The design of flaps perfectly illustrates the use of each simulation tool. The criteria of the specifications are the following (Fig. 6):

- A moderate bending of the flap spar under aerodynamic loads,

- A reasonable twist under aerodynamic pressure distributed on the flap,

- An accurately defined torsional stiffness, allowing twist angle control all along the span of the flap.

First, with iterative runs in FE beam models, the flap spar was sized. Then, a detailed composite shell FE model allowed us to confirm the preliminary results and refine global and local buckling issues. The sandwich thickness of the structural mast was driven by considerations of deformation and local buckling.

Finally, sensitivity to torsion was studied exhaustively; various fiber orientations and types of materials were tested, always keeping in mind the goal of minimum mass.

\subsection{Overall check}

One important requirement on the whole design was the ability to manoeuvre the boat and the wing-sail in various sails/rigging configurations, depending on the breeze and the sea state. Even with the construction well advanced, we built a complete composite shell FE model of the main element to analyse the different loadcase scenario and check the interactions between each parts of the main element structure.

An example that shows the interest of this complete FE model is the main element trailing edge buckling issue (Fig. 7)

The stiffness of the main element comes from the main spar. To create the aerodynamic shape of the airfoil, a fairing is required, and this fairing is held by a "skeleton", which is another carbon structure behind the structural mast. The challenge was to tune the stiffnesses of the various elements to prevent buckling of the main element trailing edge (Fig. 7).

As shown in Figure 7, the entire structure supporting the aft fairing was modelled, and mechanical solutions were designed to overcome this problem of local buckling.

\section{Mass optimization}

The calculation of the overall structure of the wingsail was done in two main steps. The first one was to define a main spine that could carry the aerodynamic forces and transfer these loads into the platform. The second step was to design the frame structure able to create and maintain the outer shape of the wing-sail. Optimization of this second item was essential given the challenge of developed area, thus the mass involved.

\subsection{Outer shape}

The outer shape must allow the wing-sail to maintain its aerodynamic shape. Indeed the loads applied on this skin are the aerodynamic pressures, either positive or negative, respectively on the pressure and succion side of the profile. After some various testings, the choice was made on a heat-shrinkable membrane.

Under the effect of heat, the membrane shrinks and tightens like a drum skin. The greater the pretension, the 


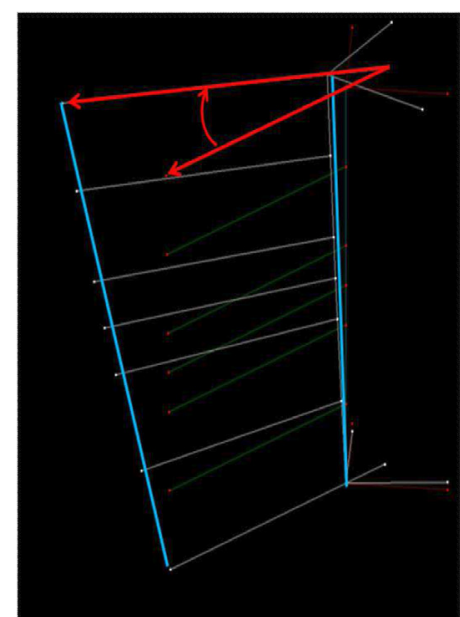

Beam model of a flap

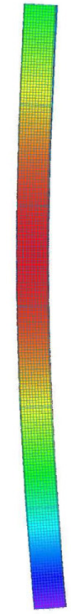

Flap spar detailed model

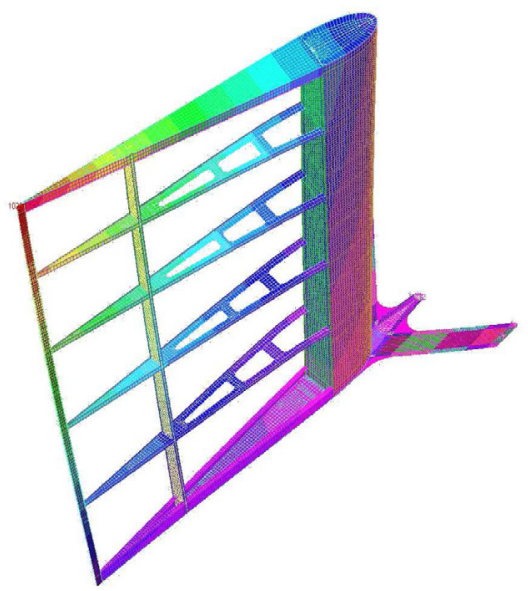

Entire flap structure model

Fig. 6. Design steps of a flap.

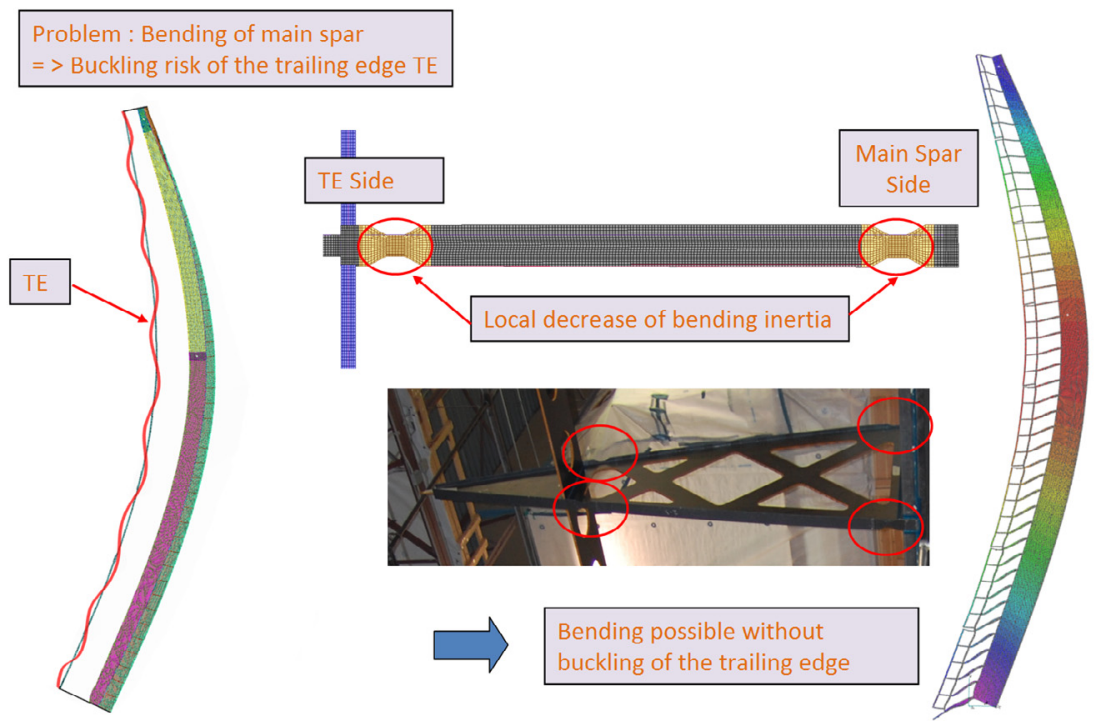

Fig. 7. Bending of the main element.

lower is the deflection induced by the sollicitation of the pressure field. The downside of higher pretension is an increase in the forces generated on the internal structure.

Many tests of films with different heat treatments were conducted to determine the best compromise film/internal structure.

\subsection{Internal structure}

The internal structure is similar on the main element and on the flaps. This structure carries the aerodynamic loads to the main structure and holds the pre-tension loads of the film. This skeleton is made of a system of frames similar to an I-beam: two carbon flanges either side of a web made of sandwich panels.

These sandwich panels are the wen that works mainly in shear. Keeping in mind every weight savings, the design team benefited from the experience of BMW engineers for topological shape optimization (Fig. 8).

The use of all these different techniques in the service of optimizing mass gave birth to a rigid wing-sail which weighed close to the mast/boom/mainsail package it replaced.

\section{Composite buckling issues}

In this section we wish to present two cases of composite buckling [3] which we faced with in the development of the wing-sail and for which the numerical results do not reflect reality:

- The local buckling of thin-shell monolithic composite, - The buckling of composite sandwich. 


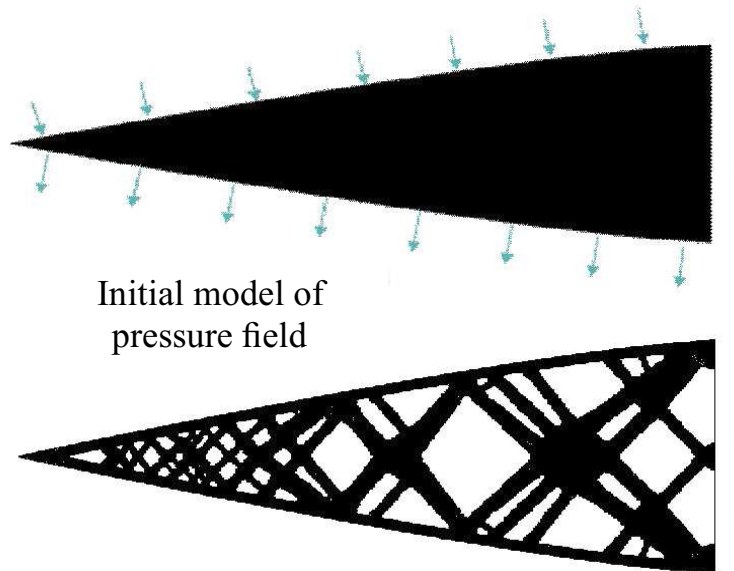

Topological shape optimization result

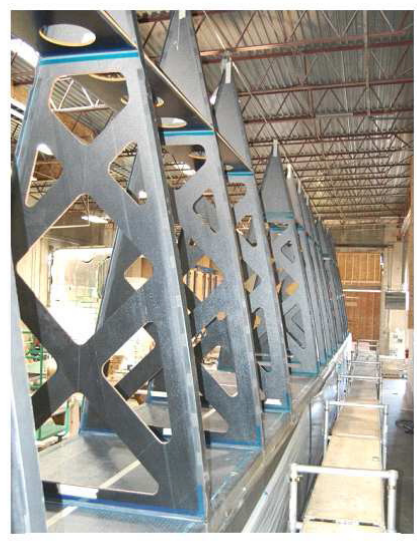

Achievement

Fig. 8. Topological shape optimization of the ribs.

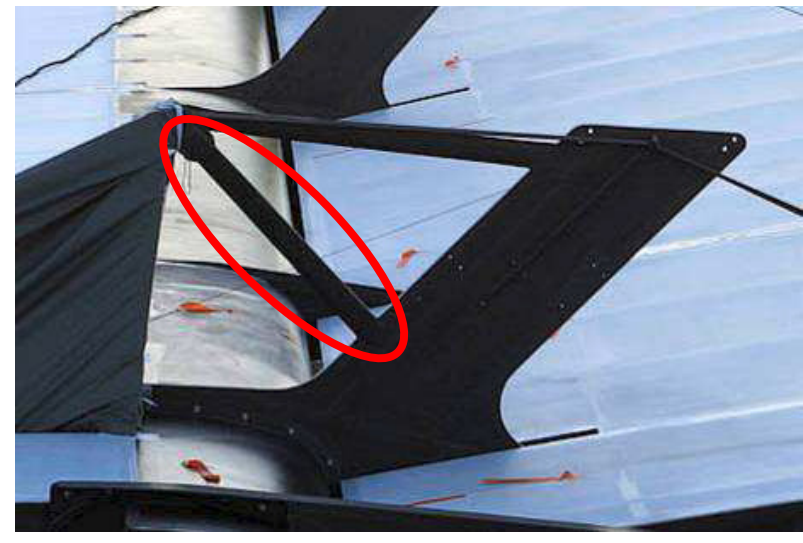

Fig. 9. Modeled tube.

\subsection{Local buckling calculation of a monolithic streamlined tube}

One of the design criteria of a monolithic tube is the local buckling. The goal of a local buckling calculation is to determine the critical buckling stress for a section of mast in compression. The numerical model is built using NX NASTRAN software.

We present in this section the results for the spreader profiled tube involved in the control system of wing-sail shown in Figure 9.

The scantling highly anisotropic of this tube is constant over the entire section: a typical laminate is $[\backslash / \||| \mid \backslash /]$ with:

$-[\backslash /]:+/-45^{\circ}$ ply;

- [l]: unidirectional ply oriented along the principal direction, i.e. along the axis of the tube.

The section of tube modeled is long enough to avoid any side effects. We use pinned-pinned boundary conditions, and the tube section is loaded in compression.

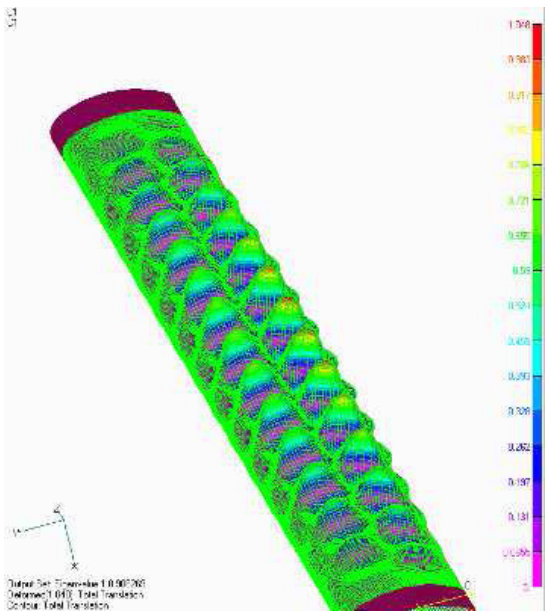

Fig. 10. First local buckling eigenshape.

The calculation is a linear buckling calculation, search for eigenvalues. We are looking for the first local buckling eigenmode.

\subsubsection{Numerical model NX NASTRAN "laminate"}

NX NASTRAN model "laminate" is a composite layup model that uses implicitly the membrane equivalent modules.

The calculation gives $\sigma_{\text {CruD }}=-250 \mathrm{MPa}$ and the eigenshape shown in Figure 10.

Following this result, we can notice that:

- The result is low compared to observations. Indeed, we know from experience that such a tube can withstand higher stresses without buckling issues.

- The buckling eigenshape shows bending waves rather than membrane waves. 

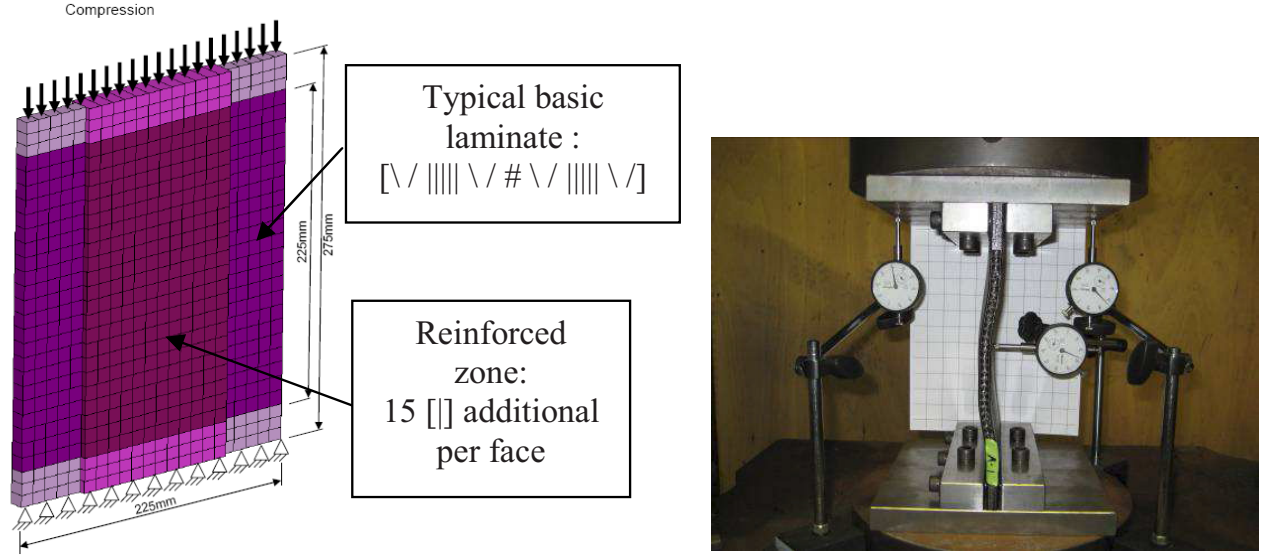

Fig. 11. Composite sandwich panel: modeling and experimentation.

\subsection{2 "Orthotropic" numerical model}

In agreement with the eigenshape, we use, in this model, the bending equivalent modules of the material from the matrix $[\mathrm{D}]$. The calculation gives : $\sigma_{\mathrm{cr}_{\mathrm{UD}}}=$ $-457 \mathrm{MPa}$, result which differs from a factor 1.8 in comparison with the "laminate" model.

The observations show that we can have much more confidence in this model than in the first one.

\subsubsection{Interpretation}

The problem is that buckling calculation requires the use of membrane or bending equivalent modules according to the local buckling eigenshape that we cannot predict a priori. It's the job of the engineer who must "choose" its modules. This problem remains an open question.

\subsection{Sandwich composite buckling calculation}

We compare in this section some buckling results of a sandwich composite panel. This panel is representative of one side of the wing-sail main element main spar. The results are from three different softwares (NX NASTRAN, ABAQUS, and NISA 7) and from one experiment made by BMW Oracle Racing team. For confidentiality reasons, we will not exactly detail here the experimental approach. We only present an outcome from this experiment useful to the presentation.

\subsubsection{Modelling and experimentation}

We work on a sandwich panel with a honeycomb core (Nomex $48 \mathrm{~kg} \cdot \mathrm{m}^{-3}$ ). The basic laminate of this panel is $[\backslash /|||| \backslash /$ \# $\backslash /|||| \backslash /]$, with:

$-[\backslash /]:+/-45^{\circ} \mathrm{ply}$

- [l]: unidirectional ply oriented along the principal direction;
- [\#]: Nomex $48 \mathrm{~kg} \cdot \mathrm{m}^{-3}$ core, $8 \mathrm{~mm}$ thick. 15 [l].

Each skin of this panel is reinforced at the center by

The panel is compressed to its ruin (Fig. 11).

The calculation is a calculation of linear buckling, search for eigenvalues, performed with three different softwares: NISA 7, NX NASTRAN, ABAQUS.

\subsubsection{Results and observations}

The results for the first buckling eigenmode are shown in Figure 12. The left figure is representative of the results of numerical models NX NASTRAN and ABAQUS; the right one is representative of experimental results and the numerical model NISA 7.

We can see in Figure 13 that the eigenshapes given by NX NASTRAN and ABAQUS are physically difficult to interpret. A mesh refinement does not solve the problem: critical load and buckling wavelength decrease, eigenshape profile remaining the same type. Refining a lot, it is even possible to obtain a buckling wavelength smaller than the thickness of the laminate!

The eigenshapes given by NISA 7 are more realistic and close to the experimental eigenshape but the experimental critical load is 2 times lower than the one calculated numerically.

Thus the interpretation of these buckling results of sandwich composite remains an open question.

\section{Conclusions}

In this paper, we presented our approach in the project of the wing-sail of the maxi trimaran BMWOracle. The project schedule was very tight - phases of design, modeling and construction had to be completed in 6 months - that's why we used classic tools in a pragmatic way.

Some computational problems of buckling of composite material monolithic and sandwich again appeared with 


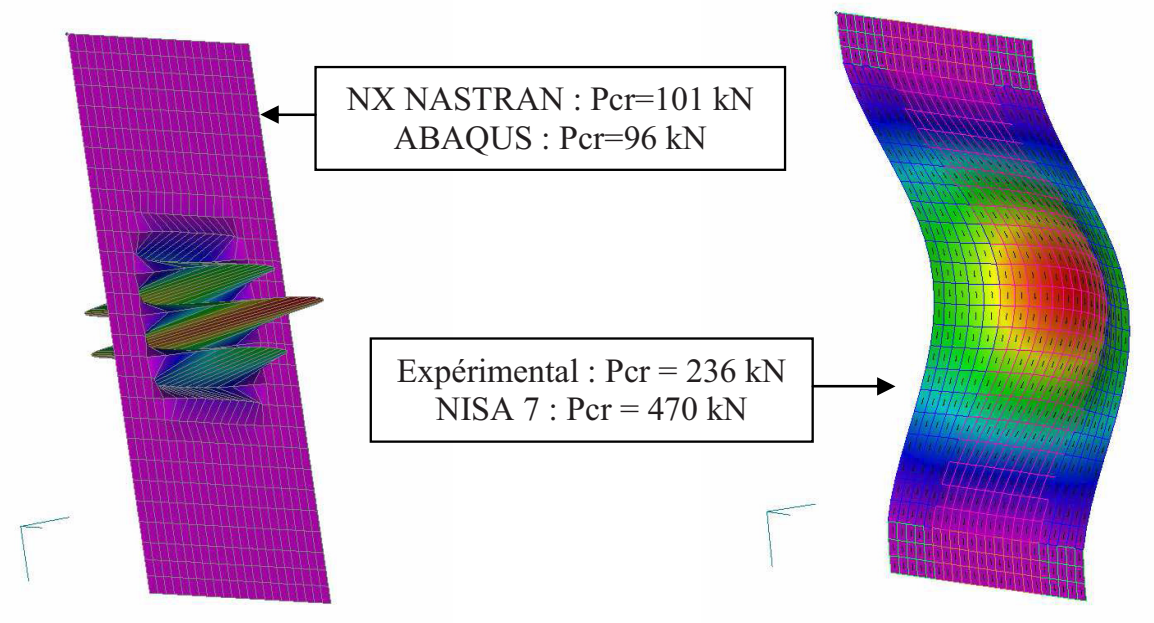

Fig. 12. Critical Loads Pcr and associated eigenshapes.

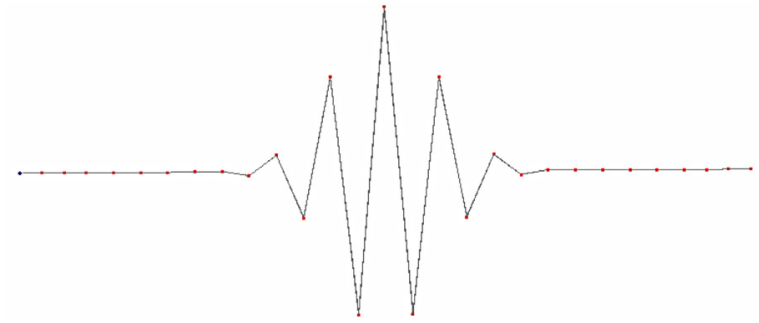

Fig. 13. Eigenshape profile obtained with NX NASTRAN and ABAQUS: red points represent consecutive nodes of the structure.

this study. Nowadays we don't have any theoretical solutions, thus we're still applying empirical methods.

\section{References}

[1] P. Casari, D. Choqueuse, P. Davies, H. Devaux, Application marine des matériaux composites, Cas des voiliers de compétition, Techniques de l'Ingénieur, AM5 655, 2008

[2] H. Devaux, R. Balze, P. Pallu De la Barrière, J. Védrenne, SimSpar: an efficient tool for mast design and tuning, Innov'sail, Lorient, May 2008

[3] H. Devaux, Global and local buckling of composite materials, in Proceedings Ifremer conference on nautical construction in composite materials, Paris, 1992 